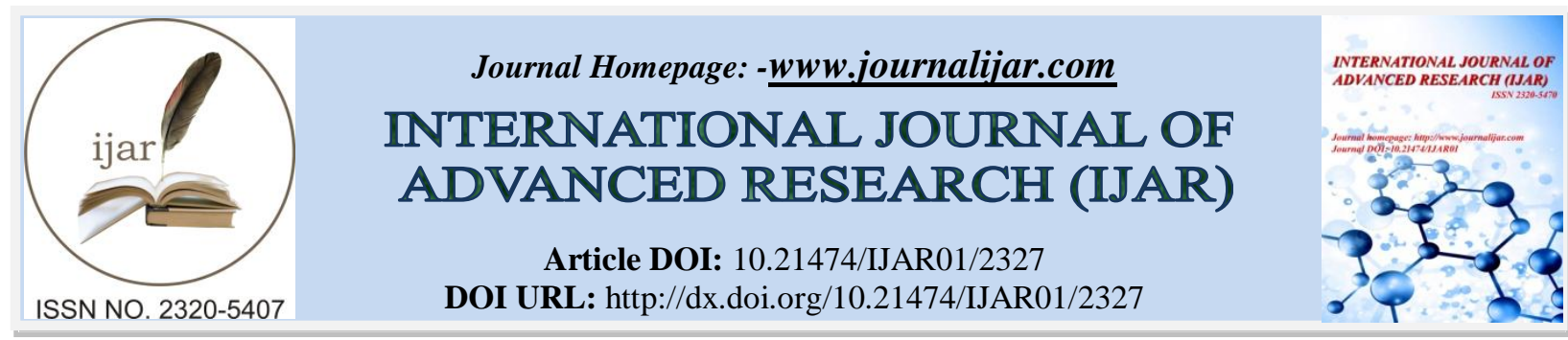

RESEARCH ARTICLE

\title{
Zinc Oxide Photocatalytic Decolourization ofBlack Tea (Camellia sinensis) wastewater from processing Factories in Kenya.
}

"Patrick K.Tum ${ }^{1}$, David K. Kariuki ${ }^{1}$, Fredrick D.O. Oduor ${ }^{1}$ and John K. Wanyoko ${ }^{2}$.

1. University of Nairobi, School of Physical Sciences, Department of Chemistry, P.O Box 30197-00100 Nairobi, Kenya.

2. Tea Research Institute of Kenya, P.O Box 861-20200, Kericho, Kenya.

\section{Manuscript Info}

Manuscript History

Received: 30 September 2016

Final Accepted: 30 October 2016

Published: November 2016

Key words:-

Black tea wastewater, decolourization, photocatalytic, zinc oxide

\begin{abstract}
Decolourization of persistent brick-red colour of black tea processing wastewater was investigated. Wastewater samples were collected from three black tea processing factories in the western Kenya tea growing highlands and were subjected to photocatalytic reaction on zinc oxide semi-conductor. An amount of $500 \mathrm{~cm}^{3}$ of wastewater was put in the photocatalytic reactor with a floor coated with a thin layer of $\mathrm{ZnO}$ to give a water height of cca $2 \mathrm{~cm}$. This was illuminated with artificial UV lamp producing radiation at wavelength $365 \mathrm{~nm}$ of intensity 3.0 $\mathrm{mW} / \mathrm{cm}^{2}$ for $3 \mathrm{hrs}$. A second set of experiments was carried out using solar light of intensity $1.4 \mathrm{~mW} / \mathrm{cm}^{2}$. Samples of $5 \mathrm{~cm}^{3}$ were drawn every 15 minutes and analyzed using UV/Vis spectrophotometer at $\lambda=410$ $\mathrm{nm}$. A total of 48 analytes showed decolourization of $77 \%-87 \%$ of the brick-red colour in $3 \mathrm{hrs}$. Solar illumination produced higher efficiency of decolourization of $3 \%$ above UV lamp. On average decolourization of $61 \%$ solar and $58 \%$ UV lamp was achieved in 60 minutes although solar radiation intensity was less than half that of UV lamp.
\end{abstract}

Copy Right, IJAR, 2016,. All rights reserved.

\section{Introduction:-}

Since the 1970s, the world's population has more or less doubled raising the demand for clean and safe water for domestic consumption by six fold. In addition the demand for water required for industrial use has rapidly increased. Recent reports, such as (UN Water, 2008) indicate that nearly 80-90\% of all wastewater in developing countries is discharged directly into surface water bodies. Another UN report indicates that by 2025, two-thirds of the population of the world could face water stress (UNEP, 2007). Kenya has been categorized as water scarce country i.e. with 647 $\mathrm{m}^{3}$ of freshwater per capita. On average black tea processing requires $50 \mathrm{~m}^{3}$ i.e. ( $\frac{1}{13}$ of available reserves) of freshwater in Kenya daily. The large volumes of wastewater generated during processing, is discharged into the natural environment without effective treatment to allow for reuse or recycling. All industries in Kenya are required to collect, treat and dispose safely all wastes generated within their areas of jurisdiction (GOK water act, 1972). The discharge of noxious wastes into water resources is prohibited (GOK EMC act, 1999). These wastewaters from the tea factories are loaded with various pollutants such as high organic matter, high suspended matter, heavy metals, odour, surfactants and high oxygen demanding parameters that make the water unpalatable. The greatest concern for the whole tea industry in Kenya, is the persistent problem of the colour of wastewater (brick-red). Polyphenols present in the wastewater generated during tea processing, colours the wastewater to brick-red. Black tea 
polyphenols have conjugated carbon-carbon double bonds in their structure that causes the brick-red colour of tea wastewater (Graham, 1992). The main culprit responsible for colouring the wastewater are theaflavins (Maghanga et al., 2009).

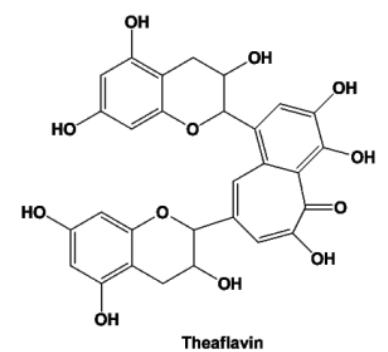

Fig.1:- Theaflavins (India Tea Research Institute)

Conventional methods of wastewater treatment such as flocculation and coagulation have proved ineffective in the removal of the brick-red colour of tea wastewater. Photocatalysis as a novel wastewater treatment technique, is a light induced process that results in the oxidation of organic molecules through redox reactions activated through the electron-hole pairs generated on the surface of metal oxide semiconductors e.g. ZnO, upon beyond band gap light irradiation ( Liu et al., 2011). The cleavage of the conjugated carbon-carbon double bonds of polyphenols by (.OH) radicals leads to the decolorization and subsequently the mineralization to $\mathrm{CO}_{2}$ and $\mathrm{H}_{2} \mathrm{O}$. The source of UV irradiation for this study was in the form of artificial UV lamps and solar light irradiation. Solar energy photocatalysis on heterogeneous photocatalysts is a promising sustainable process for environment remediation while its viability in practice highly depends on effective photocatalysts (Ajmal et al., 2014; Tachibana et al., 2012). Several researchers have indicated that $\mathrm{ZnO}$ semi-conductor photocatalyst demonstrates high photocatalytic efficiencies for the degradation of organic pollutants (Strunk et al., 2009; Gilmore, 2003; Ullah and Dutta, 2008; Huang et al., 2012). Zinc oxide powder photocatalyst is a promising semi-conductor, due to its high photosensitivity and nontoxicity, though it can only utilize a small portion of solar energy (3-5\%) in the UV region owing to their large bandgap (Pelaez et al., 2012; Liu et al., 2011). Zinc oxide has been known to be a suitable alternative to $\mathrm{TiO}_{2}$ so far as band gap energy is concerned and in fact a higher photocatalytic efficiency compared with $\mathrm{TiO}_{2}$ have been reported for $\mathrm{ZnO}$ (Hayashi et al., 2007; Huang et al., 2008). Degradation may take place either through electron extraction from organic pollutants by the holes of excited $\mathrm{ZnO}$ or hydroxide radical mediated decomposition of organic pollutants. As a suitable semi-conductor, $\mathrm{ZnO}$ absorbs a photon of energy equal to or greater than its band gap width $(3.2 \mathrm{eV})$, an electron may be promoted from the valence band to the conduction band leaving behind an electron vacancy or hole in the valence band.

$\mathrm{ZnO}+\mathrm{UV} \rightarrow$ electron $\left(\mathrm{e}^{-}\right)+$positive hole $(\mathrm{h}+)$ (formation of electron-hole pair).

As a remedy for environmental pollutantion, $\mathrm{ZnO}$ as a semi-conductor photocatalyst has received attention from many researchers including ( $\mathrm{Li}$ et al., 2007). The main objective of the study was to develop an effective system to decolourize wastewater discharged from tea processing factories using zinc oxide as a photocatalyst by artificial UV and solar light.

\section{Material and methods:-}

\section{Materials:-}

Tea processing wastewater samples were collected from three tea processing factories in Nandi county, Kenya, namely Chebut $\left(0^{\circ} 12^{\prime} 14^{\prime \prime} \mathrm{N}, 35^{\circ} 6^{\prime} 18^{\prime \prime} \mathrm{E}\right)$, Nandi Tea $\left(0^{\circ} 5^{\prime} 32^{\prime \prime} \mathrm{N}, 35^{\circ} 11^{\prime} 20^{\prime \prime} \mathrm{E}\right)$ and Kibwari $\left(0^{\circ} 3^{\prime} 0^{\prime \prime} \mathrm{N}, 35^{\circ} 7^{\prime} 60^{\prime} \mathrm{E}\right)$. The wastewater samples were collected at the point of exit from the factories and stored under refrigeration at $4^{\circ} \mathrm{C}$ for preservation (APHA, 1992). Commercial $\mathrm{ZnO}$ and $\mathrm{TiO}_{2}$ powder photocatalysts was purchased by Science lab Chemicals, Nairobi, Kenya. All other chemicals and materials used in the study were of analytical grade and used without further purification.

\section{Preparation of $\mathrm{ZnO}$ coated layer:-}

Layers coated with immobilized $\mathrm{ZnO}$ powder were prepared by sedimentation from an aqueous suspensions of concentration $10 \mathrm{~g} / \mathrm{l}$ on a degreased and clean glass plate (borosilicate) of dimensions $(18 \mathrm{~cm} \times 13 \mathrm{~cm})$. The catalyst suspensions were pre-treated using an ultra-sound decibel(Model- UP2005 ultrasonic homogenizer)to break down any agglomerates present and making the suspension uniform. The prepared layers are placed on a ceramic tile and allowed to dry at room temperature for about 45 mins and then dried in an oven for 2 hrs. The dried layers were 
further annealed at $200^{\circ} \mathrm{C}$ for 30 mins to fixate the particles. $28.8 \mathrm{~cm}^{3}$ of the catalyst suspension was immobilized to ensure an optimum catalyst loading of $0.5 \mathrm{mg} / \mathrm{cm}^{2}$.

\section{Photoreactor prototype and reaction set-up}

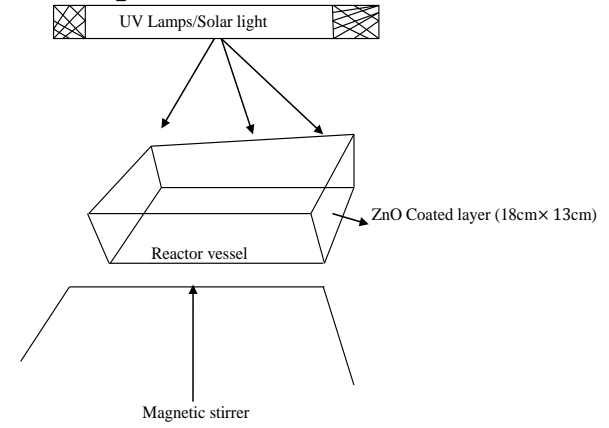

Fig. 2:- Batch photocatalytic degradation reactor

The decolourization experiments were done in a batch photoreactor $(20 \mathrm{~cm} \times 15 \mathrm{~cm} \times 10 \mathrm{~cm})$ as shown in fig. 2 above. A filtered volume of $500 \mathrm{~cm}^{3}$ of the wastewater was placed into the reactor. The reactor was placed on a magnetic stirrer to ensure perfect mixing. As a source of UV light, artificial UV lamps and solar energy were used. The coated layer was inserted to the base of the reactor. The dimensions of the reactor were $(18 \mathrm{~cm} \times 13 \mathrm{~cm})$ inserted to the bottom of the rectangular reactor. The distance between the surface of the solution and the UV lamps cca. $10 \mathrm{~cm}$.

\section{Artificial UV/ZnO coated layer photocatalytic decolourization experiments}

Two 15W near UV (black light) fluorescent lamps are used for irradiation with UV light. The fluorescent tubes emit light of wavelengths between $320-400 \mathrm{~nm}$ at a height of $10 \mathrm{~cm}$. The average measured radiation flux density was 3.0 $\mathrm{mW} / \mathrm{cm}^{2}$ to supply UV photons to the photoreaction. The reaction takes place at room temperature.

\section{Solar light/ZnO coated layer photocatalytic degradation experiments}

For this set of experiments sunlight was used to supply UV photons. The average measured solar irradiation flux density for Nandi County measured at $1.45 \mathrm{~mW} / \mathrm{cm}^{2}$ over the duration of the photocatalytic degradation reactions. The reaction takes place at room temperature.

\section{Analyses:}

Changes in effluent colour with irradiation time was determined with a spectrophotometer (UV- Cecil 2020) for absorbance measurement and (UVP radiometer) for UV light irradiation flux density. The efficiency of the decolourization system was determined by calculating the percentage of colour removal with irradiation time.

\section{Results and Discussions:-}

\section{UV/Vis spectra for raw wastewater}

From the graph, effluent from Chebut shows a lower absorbance. Effluent from Kibwari and Nandi tea are higher compared to Chebut and almost similar. Nandi Tea and Kibwari tea processing factories are located within the same geographical area i.e. near Nandi Hills town. Chebut tea processing factory is located in Kapsabet town. Differences in soil and climatic conditions. Photocatalytic degradation experiments were measured at $\lambda=410 \mathrm{~nm}$. 


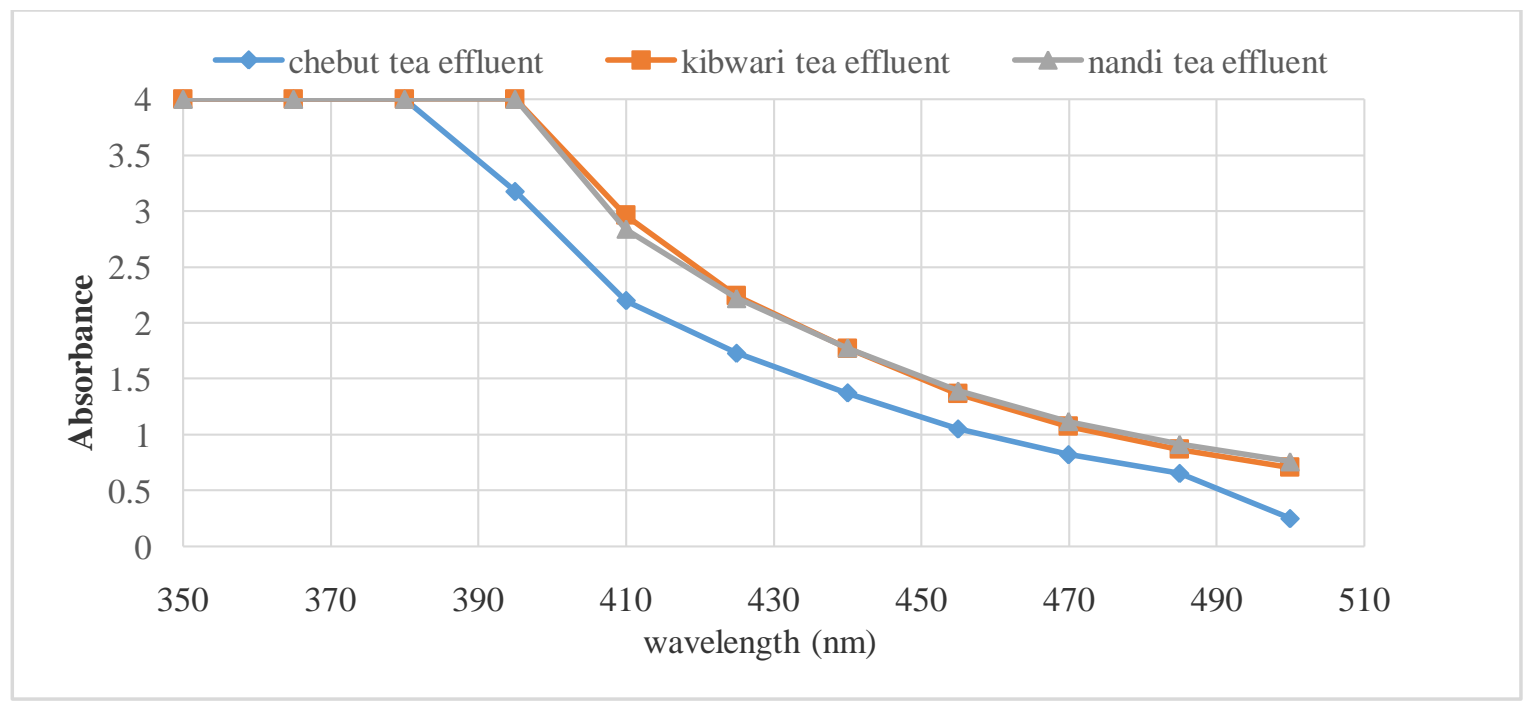

Fig. 3:- UV/Vis spectra for Chebut, Kibwari and Nandi black tea processing wastewater

Photocatalytic decolourization of tea wastewater using artificial UV light source

Experiments to remove the colour from the wastewater from Chebut, Kibwari and Nandi tea factories. The efficiency of the photocatalytic degradation to remove colour was represented as a change in absorbance at $\lambda=410$ nm over a $3 \mathrm{hr}$. duration. The results obtained are shown in fig. 4 below.

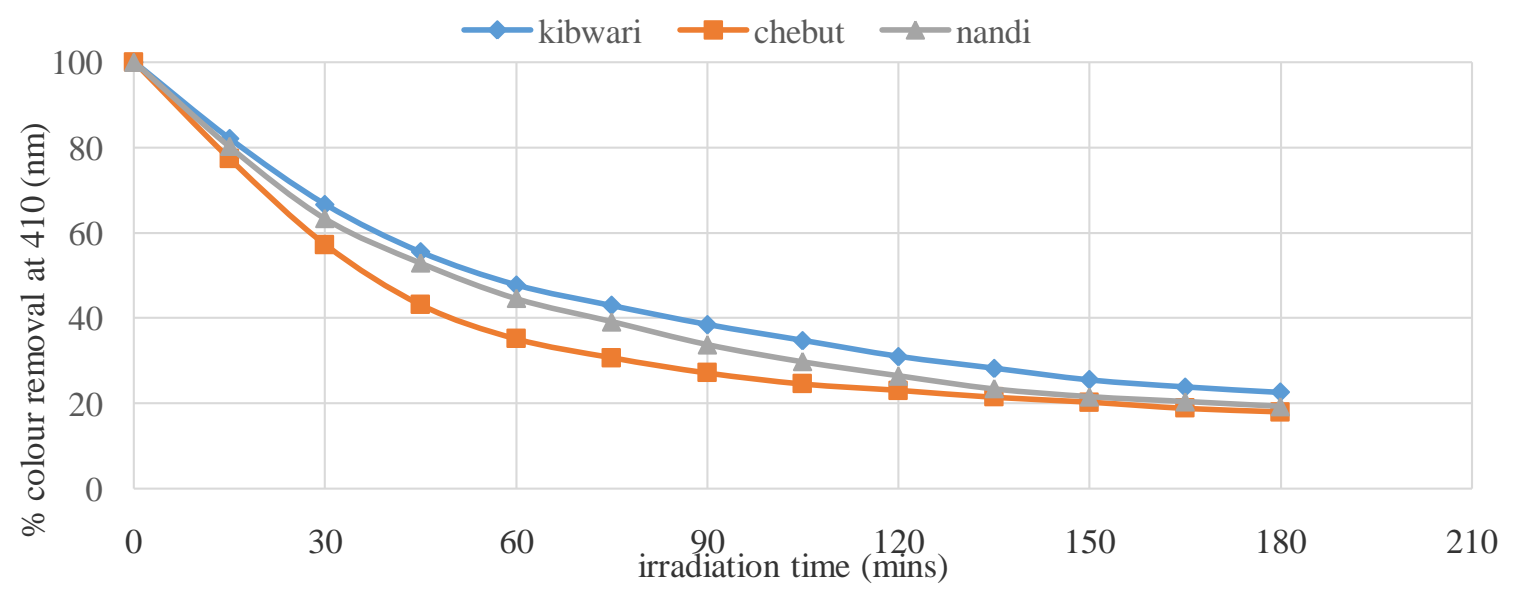

Fig.4:- Photocatalytic colour removal of wastewater by $\mathrm{ZnO}$ and artificial UV light

The results show that after $1 \mathrm{hr}$. $64.9 \%$ of Chebut, $55.5 \%$ of Nandi and $52.4 \%$ of Kibwari colour had been removed. After 3 hrs. an average of $80 \%$ of colour had been removed from the 3 samples. From fig. 3 the concentration of Chebut wastewater is significantly lower compared to Nandi and Kibwari.

\section{Photocatalytic decolourization of tea factory effluent with solar light}

Experiments to remove the colour from the wastewater from Chebut, Kibwari and Nandi tea factories. The efficiency of the photocatalytic degradation to remove colour was represented as a change in absorbance at $\lambda=410$ $\mathrm{nm}$ over a $3 \mathrm{hr}$. duration. The results obtained are shown in fig. 5 below. 


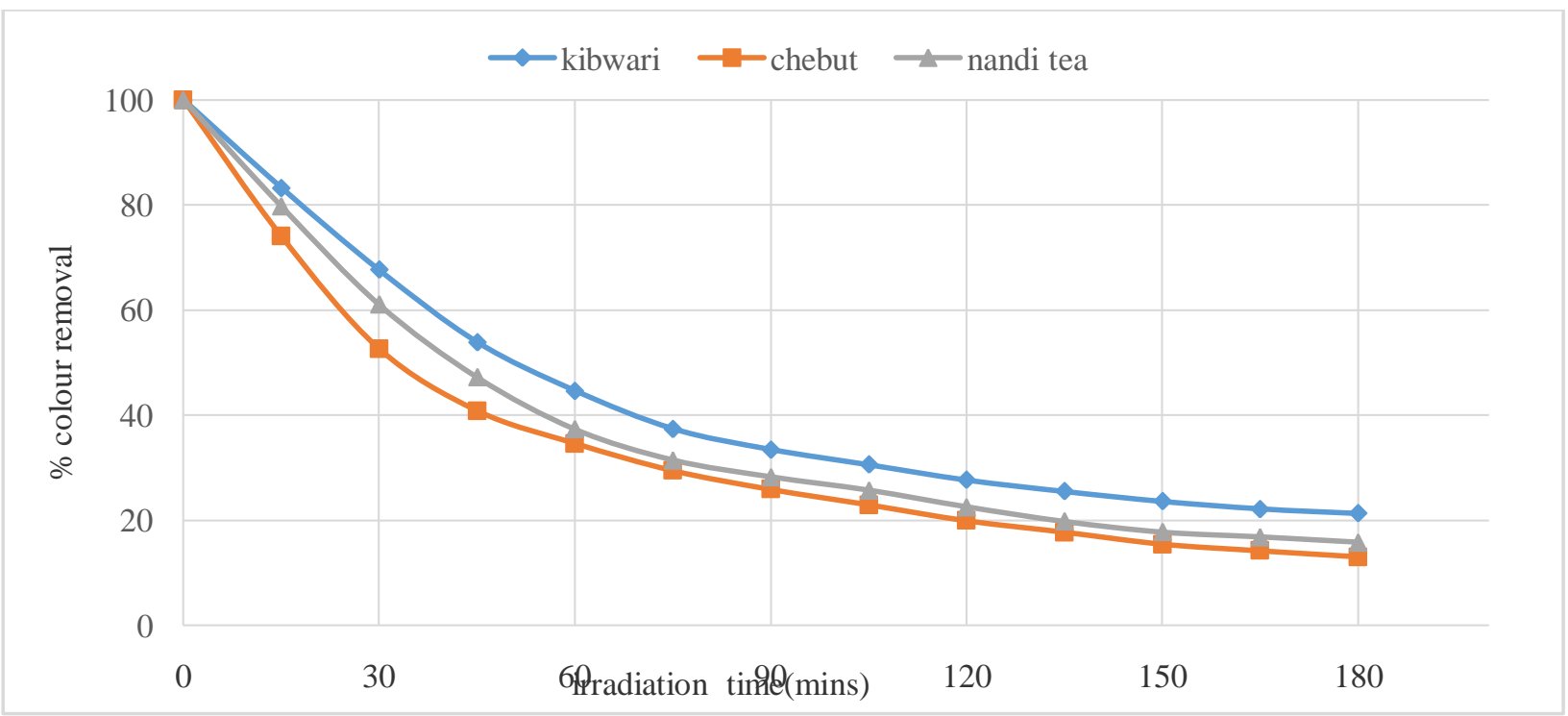

Fig. 5:- Photocatalytic colour removal of wastewater by $\mathrm{ZnO}$ and solar light light

The results show that after $1 \mathrm{hr}$. $65.5 \%$ of Chebut, $62.7 \%$ of Nandi and $55.4 \%$ of Kibwari colour had been removed. After 3 hrs. 87\% of Chebut, $84.2 \%$ of Nandi and 78.7\% of Kibwari colour had been removed. From fig.5 the efficiency of colour removal was higher in Chebut and least in Kibwari. The results are consistent with those in fig. 3 where UV photons were supplied by artificial light.

\section{comparison of decolourization efficiency between artificial UV light/Solar light:-}

The experiments in fig.6, 7 and 8 show results comparing the efficiency between the photocatalytic discolourization of wastewater by artificial UV and solar light source.

\section{Kibwari tea wastewater comparison of artificial solar UV light:-}

Solar energy experiments was slightly more efficient to artificial light. The amount of UV light irradiation from solar energy was almost 50\% lower than in artificial UV light. For Kibwari wastewater the average colour removal was $80 \%$.

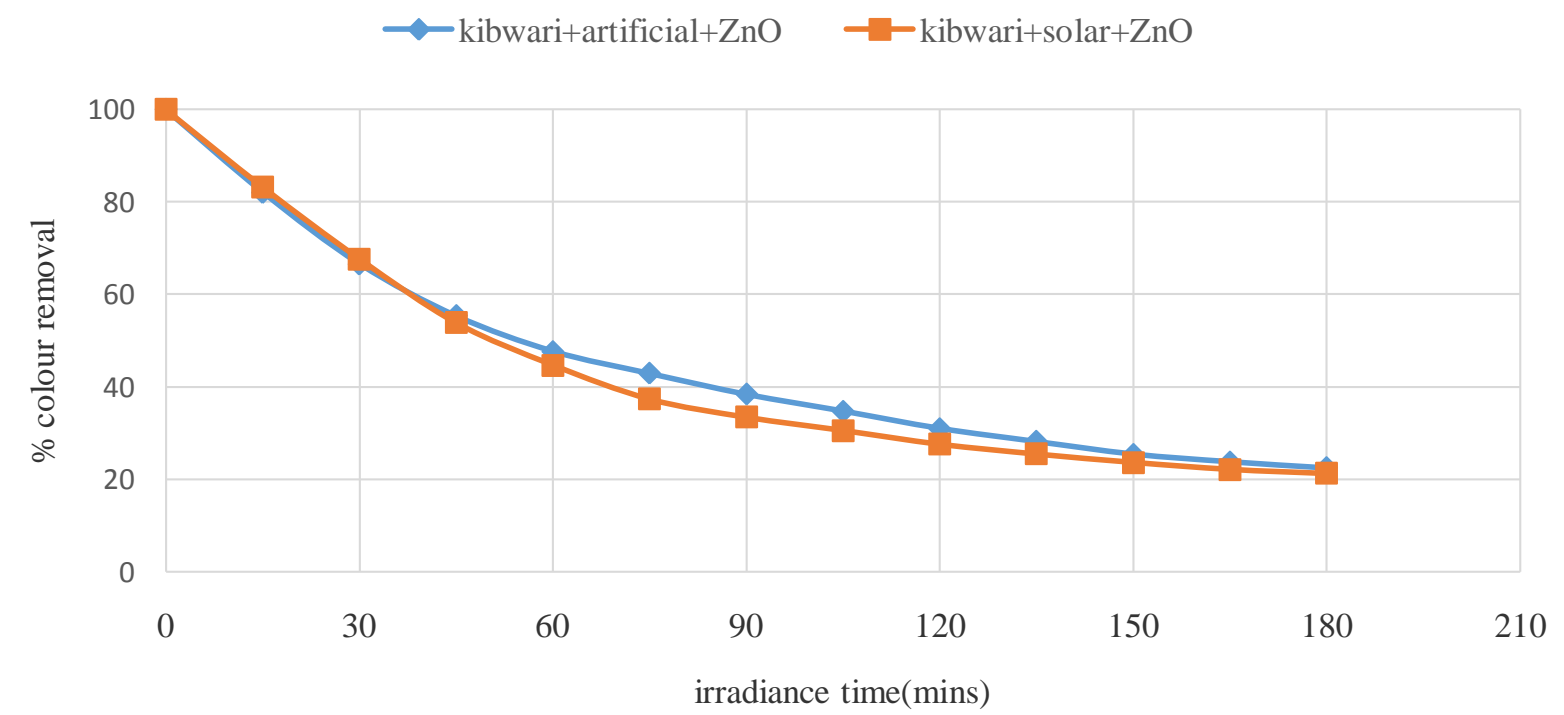

Fig. 6:- Photocatalytic decolourization Kibwari wastewater using $\mathrm{ZnO}$ and artificial UV/solar energy 


\section{Chebut tea wastewater: solar/artificial UV sources}

Solar energy experiments was slightly more efficient to artificial light. The amount of UV light irradiation from solar energy was almost 50\% lower than in artificial UV light. For Kibwari wastewater the average colour removal was $87 \%$ for solar energy and $82 \%$ for artificial UV light.

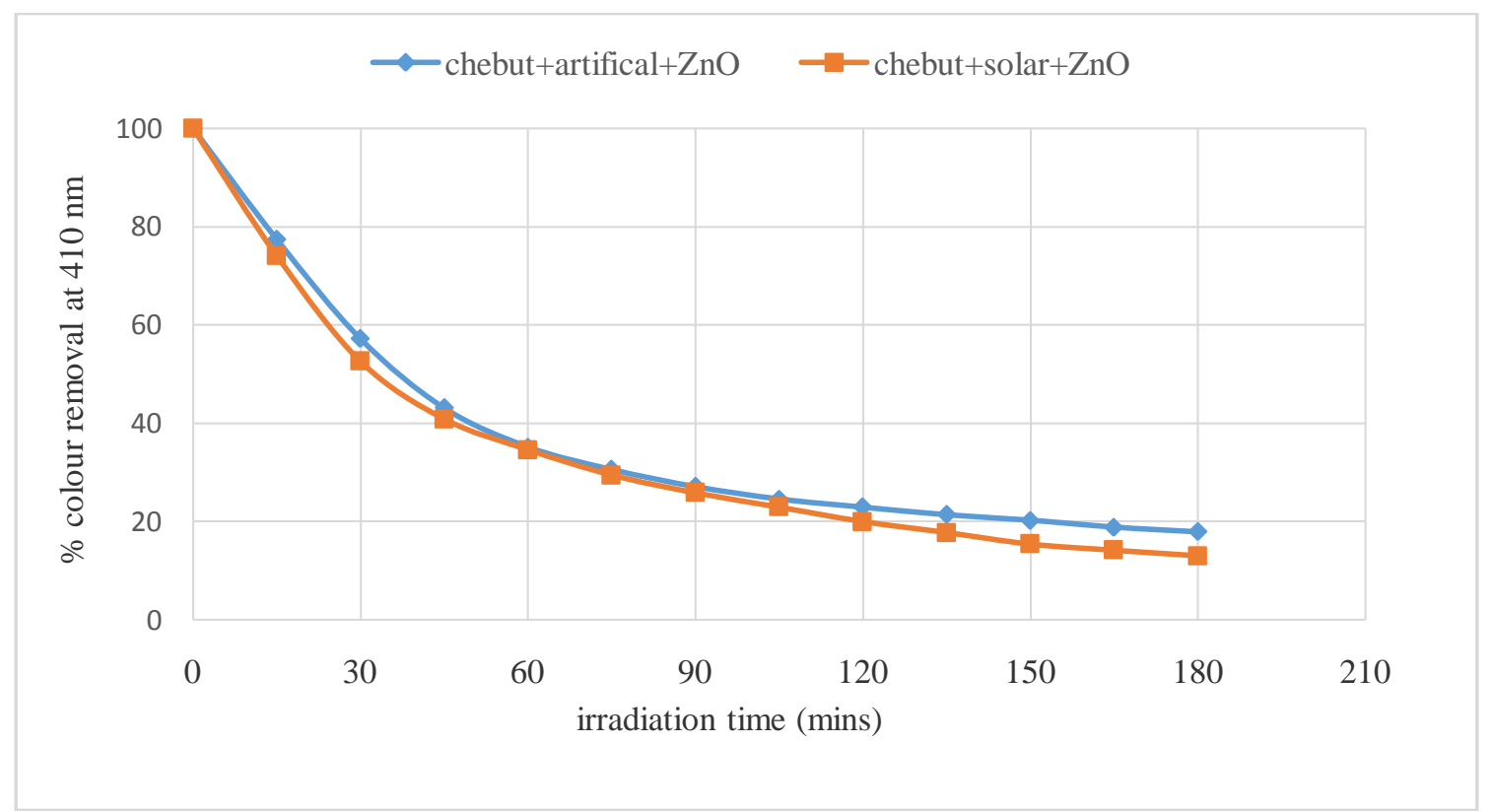

Fig. 7:- Photocatalytic decolourization Chebut wastewater using $\mathrm{ZnO}$ and artificial UV/solar energy

\section{Comparison of degradation of Nandi tea effluent solar/artificial}

Solar energy experiments was slightly more efficient to artificial light. The amount of UV light irradiation from solar energy was almost 50\% lower than in artificial UV light. For Kibwari wastewater the average colour removal was $84.2 \%$ for solar energy and $80.8 \%$ for artificial UV light.

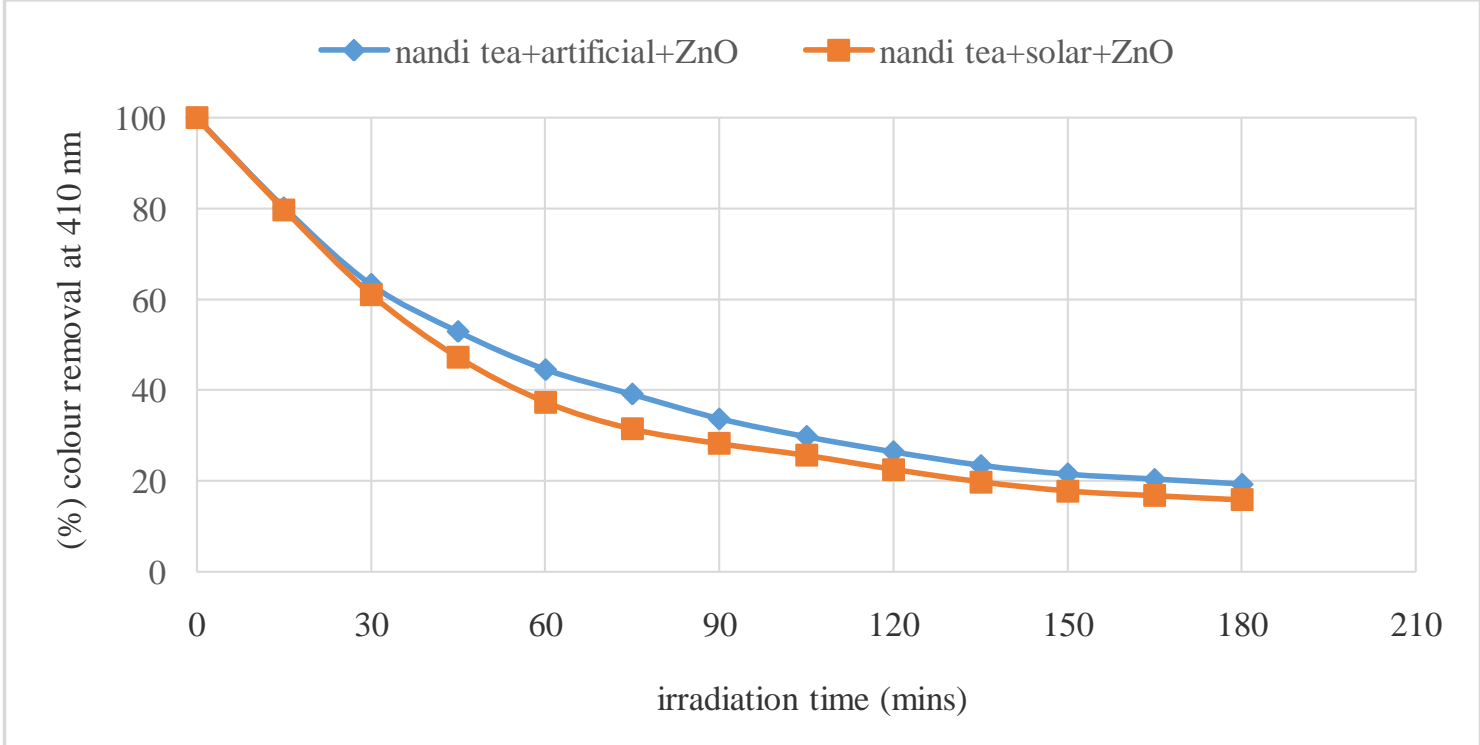

Fig. 8:- Photocatalytic degradation Nandi tea wastewater using $\mathrm{ZnO}$ and artificial UV/solar energy

\section{Conclusions:-}

From the results obtained in this study, we conclude that the photocatalytic decolourization of wastewater by discharged from Chebut, Kibwari and Nandi tea processing factories by zinc oxide/UV/solar light is viable. Further zinc oxide proved to be an effective semi-conductor photocatalyst under artificial UV light and solar light 
irradiation. The use of solar light irradiation proved efficient compared to artificial light since almost similar rates of decolourization efficiencies were achieved although the irradiation flux density was $1.4 \mathrm{~mW} / \mathrm{cm}^{2}$ for solar energy and $3.0 \mathrm{~mW} / \mathrm{cm}^{2}$ for artificial UV.

We conclude that the $\mathrm{ZnO} /$ solar energy decolourization system proved more viable compared to $\mathrm{ZnO} /$ artificial UV. This maybe as a result of the role of photosensitized oxidation in decolourization where visible light in addition to UV light initiates decolourization. These system can be scaled up to a large scale wastewater decolourization to remedy the removal of persistent brick-red colour from tea wastewater in tea processing factories in Kenya.

\section{Acknowledgements:-}

The authors are indebted to the University of Nairobi and Technical University of Kenya for the use of their facilities. The authors further appreciate the support received from Chebut, Nandi tea and Kibwari tea factories in Nandi County, Kenya.

\section{References:-}

1. Ajmal, A., Majeed, I., Malik, R.N., Idriss, H., and Nadeem, M.A. (2014).RSC Adv.,4, 37003-37026.

2. American Public Health association (APHA). (1992) Standard Methods for the Examination of Water and Wastewater, 18th ed., American Public Health Association: Washington, DC, 18-30.

3. Gilmore, F.W. (2003) Electrocoagulation Chamber and Method, United States.

4. Graham, H.N. (1992). Green tea composition, consumption, and polyphenol chemistry. Prev. Med.21, 334-350.

5. GOK Water act (cap 372) sec. 145-147 of the laws of Kenya; 1972.

6. GOK EMC Act. Environmental Management and Coordination Act; 1999.

7. Hayashi, H., Nakajima, Y and Ohta, K., (2007). Novel degradation method of organic compounds in human surroundings using iron oxide. Rep. Technol. Res. Institute Osaka Pref. 21, 79-83.

8. Huang, J., Xu, X., GU, C., Wang, W., Geng, B., Sun, Y and Liu, J. (2012). Sensors Actuators B:Chem. 173, 599-606.

9. Huang, Y.H., Huang, Y.F., Chang, P.S and Chen, C.Y. (2008). Comparative study of oxidation of dye-Reactive Black B by different advanced oxidation processes: Fenton, electro-Fenton and photo-Fenton. J. Hazard. Mater.154, 655-662.

10. Liu, S., Li, C., Yu, J and Xiang, Q. (2011). Cryst. Eng. Comm, 13, 2533-2541.

11. Li, J.H., D.Z. Shen, J.Y. Zhang, D.X. Zhao, B.S. Li, Y.C. Liu and X.W. Fan, (2007). The effect of $\mathrm{Mn}^{2+}$ doping on structure and photoluminescence of $\mathrm{ZnO}$ Nano films synthesized by sol-gel method. Journal of Luminescence, 122, 352-354.

12. Maghanga, J.K, Segor, F.K, Etiegni L and Lusweti, J.K. (2009). Electrocoagulation method for colour removal in tea effluent. A case study of Chemomi Tea factory in Rift Valley, Kenya. Bull. Chem. Soc. Ethiop., 23(3),371-381.

13. Pelaez, M., Nolan, N.T., Pillai, S.C., Seery, M.K., Falaras, P., Kontos, A.G., Dunlop, P.S.M., Hamilton, J.W.J., Byrne, J.A., O'Shea, K., Entezari, M.H and Dionysiou, D.D. (2012). Appl. Catal., B, 125, 331-349.

14. Strunk, J., Kaher, K., Xia, X and Muhler, M. (2009). Surf. Sci. 603, 1776-1783.

15. Tachibana, Y., Vayssieres, L and Durrant, J.R. (2012). Nat. Photonics, 6, 511-518.

16. Ullah, R and Dutta, J. (2008). J. Hazard. Mater. 156, 194-200.

17. UN Water 2008, tackling a global crisis: International Year of Sanitation 2008, viewedFebruary 2010, http://www.wsscc.org/fileadmin/files/pdf/publication/IYS 2008tackling a global crisis.pdf.

18. UNEP 2007, Global Environment Outlook Geo4 environment for development, viewed 28th May 2013,http://www.unep.org/geo/geo4/media/. 